\title{
COMWENTABY \\ Scarce Resources for Nuclear Detonation: Project Overview and Challenges
}

C. Norman Coleman, MD; Ann R. Knebel, DNSc, RADM-USPHS; John L. Hick, MD; David M. Weinstock, MD; Rocco Casagrande, PhD; J. Jaime Caro, PhD; Evan G. DeRenzo, PhD; Daniel Dodgen, PhD; Ann E. Norwood, MD; Susan E. Sherman, JD; Kenneth D. Cliffer, PhD; Richard McNally, MS; Judith L. Bader, MD, CAPT-USPHS; Paula Murrain-Hill, MPH

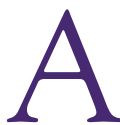
terrorist nuclear detonation of 10 kilotons would have catastrophic physical, medical, and psychological consequences and could be accomplished with a device in a small truck. Tens of thousands of injured and ill survivors and uninjured, concerned citizens would require medical care or at least an assessment and instructions. In proximity to the incident location, there would be a huge imbalance between the demand for medical resources and their availability. ${ }^{1-3} \mathrm{Be}-$ yond the immediate blast area, much of the infrastructure would remain intact. Most people would reach medical care by selfreferral and require sorting and assessment to determine what medical intervention is necessary, appropriate, and possible.

No society has the resources to deliver the full spectrum of care needed in the time frame required. Yet, careful planning and a clear understanding of how best to allocate scarce resources, triage and evacuate patients, and implement crisis standards of care have the potential to save thousands of lives and provide comfort to those unlikely to survive. The US government and nongovernment experts continue to develop planning guidance, ${ }^{1,4-8}$ medical countermeasures, ${ }^{9,10}$ and medical specialty capacity and capabilities. ${ }^{11-13}$ This Scarce Resources for a Nuclear Detonation Project provides data, supporting information, and tools for medical planners and responders to address the issues of scarce resources ${ }^{14}$ and plan for triage and resource allocation in the first 4 days postdetonation, when there will be severe shortages.

\section{PROJECT ORGANIZATION}

Recognizing the imperative to plan for such an incident, the Assistant Secretary for Preparedness and Response (ASPR) in the US Department of Health and Human Services convened a panel of subject matter experts (the participant list and details of the manuscript preparation process are found in the Appendix) to answer the question, "What do I do?" and to provide practical tools for individuals involved in planning for and response to this scarceresources setting. The resulting articles in this special issue of $\mathrm{Di}$ saster Medicine and Public Health Preparedness are not intended to be exhaustive reviews, and they reflect the judgment and opinion of the experts, not those of the governmental agencies or academic institutions that employ them. ${ }^{14-22}$ The recommendations are based on the available data, recognizing that the human and animal data on radiation injury alone and on combined injury are limited.

Model output for casualty types and number are described in a general manner. ${ }^{15}$ (The Department of Health and Human Ser- vices has detailed models from which the data and guidance in these articles are based for the consequences of nuclear detonation in a range of cities, from a variety of heights of burst, and under a range of meteorological conditions, and for scarcity of specific resources for medical management of acute radiation syndrome. The detailed data are for restricted use and not publication.) This work builds on previous contributions that focused on scarce resources in pandemic influenza. These include a series of articles in Chest, ${ }^{23-27}$ ethical guidance by the Department of Veterans Affairs, ${ }^{28}$ a letter report on crisis standards of care by the Institute of Medicine ${ }^{2}$ monographs on mass medical care with scarce resources, Mass Medical Care With Scarce Resources: A Community Planning Guide $e^{29}$ and Mass Medical Care With Scarce Resources: The Essentials, ${ }^{30}$ which ASPR developed in collaboration with the Agency for Healthcare Research and Quality and others. Many of the principles in this special issue pertain to scarce resource situations in general, but these articles address issues specific to the unique characteristics of a nuclear detonation.

\section{SUMMARY OF ISSUES AND CHALLENGES}

Below are high-level summaries of the issues addressed herein and some of the most important challenges according to the experts. Detailed discussions and references are contained within the individual articles.

\section{Nuclear Detonation Incident}

The scope of the damage and spectrum of the injuries in a nuclear detonation incident depend on many factors, including but not limited to yield of device, geography, height of burst, specific location (eg, type of structures), time of day, and meteorological conditions. The physical infrastructure damage will limit transportation and access to those in need. ${ }^{15}$ The detonation will release dangerous levels of radiation immediately and also for hours to days from fallout. Combined injury (defined as physical trauma plus radiation) greatly increases the fatality risk even with maximal medical treatment, which will not be readily available. Many of the trauma casualties from blast, glass breakage, and motor vehicle crashes will have no radiation exposure, and many people in the fallout zone will have radiation exposure but no physical trauma. ${ }^{14,21}$ Understanding the expected injury types has implications for triage decision making as outlined by Coleman and colleagues. ${ }^{22}$

Four damage zones are defined in Planning Guidance for Response to a Nuclear Detonation ${ }^{4}$ and detailed by Knebel et al ${ }^{15}$ : severe dam- 
age, moderate damage, light damage, and dangerous fallout. The dangerous fallout zone footprint, in which there is sufficient radiation to produce the acute radiation syndrome, will reach its maximal extent after approximately 1.5 hours and then shrink rapidly as fallout decays. Sheltering in place for the first few hours has the potential to save many lives and reduce the severity of radiation injury in the dangerousfallout zone. Radiation will complicate search and rescue efforts and contribute to resource limitations.

Given the size of the incident in relation to the number of emergency responders, the majority of victims will reach medical care locations without prior sorting or triage. The Radiation TRiage, TReatment, and TRansport system forms the basis for organizing the response, accounting for physical damage and radiation. $4,7,8,15,20$ This conceptual approach to the medical response has the potential to maximize the available resources to save lives.

Initial triage decisions by responders will consider trauma and burns using existing triage schemes with which they are familiar. As presented in the articles by DiCarlo et $\mathrm{al}^{14}$ and Coleman et al, ${ }^{22}$ triage category will need to be modified for the presence of radiation, which will be determined by an individual's physical location during the incident and his or her signs, symptoms, and laboratory data available over time.

Initially, there will be a profound imbalance between resource supply and demand even if resource-conserving strategies are used aggressively. ${ }^{29}$ There will be heterogeneity in the availability of resources by distance from and time after the incident. Although approaches to optimizing resources may help provide structure for decisions and delay severe shortages, ${ }^{2,28}$ close to the incident there will be an immediate shift to crisis standards of care, with modification in triage order and resource allocation. Farther from the incident, resource supply and demand imbalances will be less dramatic, but they may necessitate a stepwise shift in the resource settings from conventional to contingency to crisis with the need to implement crisis standards of care. ${ }^{2}$ The rapidly changing conditions make apparent the importance of preplanning for crisis standards of care.

Casualty management follows the principles (not specific criteria) of the sort, assess, lifesaving intervention, treatment/transport/ triage scheme. ${ }^{31}$ The emphasis is on iterative assessment, because the victims' medical conditions and the availability of resources may change rapidly over time, allowing them to move from the expectant (likely to die) category into the immediate or delayed treatment categories. Palliative/comfort care is an important component of the medical response and resources should be allocated for this and for saving lives.

Following initial triage and treatment, some casualties will require expert secondary and tertiary care. The Radiation Injury Treatment Network, ${ }^{13}$ the National Disaster Medical System, ${ }^{32}$ and other centers with expertise in trauma and hematology/oncology care will be involved to the extent that their capacity allows and transportation assets are available.
The tracking of displaced people and those in need of medical care is essential, but unfortunately may be incomplete given the numbers of people involved. Individuals requiring screening for long-term radiation effects may be identified in the first days or may not be identified until much later.

Fatality management, as detailed in Planning Guidance for Response to a Nuclear Detonation ${ }^{4}$ is a secondary concern in the early hours; however, an organized approach should be implemented as soon as is reasonably possible.

\section{Challenges}

The challenges that will be faced in a nuclear detonation incident are the following:

For the initial response-communication and public understanding:

- Understanding of the need to "duck and cover" after the initial flash (to prevent blast-wave injuries from falling glass) and to shelter in place (as one would for a tornado) until further information is received

- Having familiarity with physical damage and radiation zones and the rate of change of radiation exposure

- Ensuring methods to provide timely and credible communication to guide the public on the situation and what to do/not to do to facilitate effective response

For society in general:

- Understanding that an incident of this magnitude will require unprecedented medical triage that will be extraordinarily difficult for responders and victims

- Understanding that care for people with minor injuries and routine medical conditions may be delayed for days; triage categories will need to be modified according to crisis standards; reassessment may lead to a modification of triage category

- Recognizing that providing the greatest good for the greatest number of people includes using resources for palliation and not only for saving lives

- Recognizing the critical need for consistency of public health and medical decisions across the response area; this requires preincident dialogue and preparation

\section{Ethical Considerations}

With the magnitude and suddenness of a nuclear incident, responders will be forced to operationalize medical triage that places many people who would normally receive first priority for care (immediate) into a category in which they will not receive "curative" treatment (expectant). Even medicines for symptom relief may not be available, so vast numbers of casualties may receive little or no care. Rationing of medical care will be required in a context of incomplete situational awareness. Providers will make difficult allocation decisions without the benefit of an administrative structure that could address broader optimization of resource use. 
Principles of medical ethics hold that fair prioritizing is based on a first-come, first-served approach unless this order is preempted by individuals with much greater needs for which there are available resources. The effectiveness of an intervention must be taken into account. In the scarce-resources setting it is not considered fair to allocate resources to someone who is unlikely to benefit from them. Priority for care and resources distribution will be determined by the need of the patient and the ability to meet that need with the resources available. As detailed by Caro and colleagues, ${ }^{17}$ for fair allocation, providers will apply more stringent determinations of whether an intervention will be effective (efficacy of medical intervention modified by the context) and, therefore, whether use of the resource is acceptable for that person. Whenever needs cannot be fully met, patients must still be accorded comfort, assistance, relief of symptoms, and explanations.

\section{Challenges}

The ethical challenges that will be faced are as follows:

For ethicists:

- Determining how to deal with factors such as age and preexisting comorbidities in setting priorities; it is proposed that these would be considered only to the extent they affect effectiveness of medical intervention.

- Determining how to help the medical community differentiate between efficacy of an intervention (best possible outcome) under normal circumstances and the effectiveness of an intervention (ability to complete the intervention) in the setting of critically scarce resources

- Conveying the importance of fairness and that "the greatest good for the greatest number of people" includes using some of the resources that could be used for lifesaving care to provide palliation/comfort for those who are in the expectant or delayed categories

For society in general:

- Because of unprecedented resource scarcity, there is the need to change priorities from sickest first to those with serious but more effectively managed injury, and that crisis standards will be needed in the setting of severe shortages.

- Patient characteristics such as age and prior comorbid conditions should not be used as primary considerations in triage except to the extent that they alter the effectiveness of treatment.

\section{Psychological Support}

The national and international psychological and sociological effects of a nuclear detonation would be enormous. In the 4 response zones and the surrounding communities, the overarching immediate goal of behavioral health care provider (BHCP) interventions is to support lifesaving activities and to prevent additional casualties from fallout. BHCPs can assist in the following areas:

- Promoting appropriate protective behaviors (eg, adhering to sheltering recommendations) and addressing psychological barriers to implementing them (eg, paralyzing anxiety)
- Discouraging dangerous behaviors (eg, entering dangerous fallout areas to search for loved ones)

- Helping manage patient/survivor flow to facilitate the best use of scarce resources

- Supporting first responders' and first receivers' ability to function

- Assisting with triage, including psychological triage of victims, and assisting medical triage personnel

- Delivering palliative care

At more distant sites, BHCPs should work with other health care providers to support hospitalized survivors, who are at greater risk for psychiatric morbidity and may need assistance in coming to terms with life-altering diseases or injuries (eg, blindness, limb amputations). Wherever people congregate, a BHCP's calm and empathic presence can foster a supportive environment and help restore a sense of security. BHCPs can play a consultative role to leaders, ensuring responsiveness to the changing needs of survivors. As patients at high risk for radiation sickness are identified, BHCPs can help them and their families navigate treatment decisions and expected outcomes. The month after the detonation should be used to formulate plans for longerterm mental health delivery strategies and surveillance of atrisk populations.

\section{Challenges}

The challenges faced by BHCPs are as follows:

- Expanding the capacity of the response to meet psychological needs

- Assisting responders during the incident-supporting them in real time as they make difficult triage decisions and preventing burnout by encouraging them to take periodic breaks

- Offering direct support to casualties and encouraging effective participation to help casualties and each other

- Emphasizing resilience over rage/revenge

\section{Legal Considerations}

Providers need to be informed in advance about relevant law so that concerns regarding legal liability and other legal requirements do not interfere with the willingness of clinicians to make crisis standards of care decisions to save lives. An understanding of the breadth of these laws at the federal, state, territorial, tribal, and local levels, the application of them, and how each may change in an emergency is critical to an effective response. Laws may vary from one geographic area to the next and may vary in an emergency, affording waivers or other extraordinary actions/ protections under federal, state, or local emergency powers.

Legal requirements that are commonly of concern and should be examined for flexibility, reciprocity, and emergency exceptions include liability protections for providers; licensing and credentialing of providers; consent and privacy protections for patients; occupational safety and employment protections for providers; procedures for obtaining and distributing medical countermeasures and supplies; property use, condemnation, and 
protection; restrictions on movement of individuals in an emergency area; and reimbursement for care.

\section{Challenges}

The following are the legal challenges that will be faced:

- Providing advance guidance to providers about what liability protections are available to them when they respond in their state or move between states

- Providing advance guidance to providers about what licensing requirements apply when they move between states to respond

- Developing crisis standards of care within a medical and legal framework

- Assessing what legal requirements may change or be waived in an emergency

- Assessing what further steps may be needed to ensure legal requirements support a response

\section{Triage}

Given the complexity of the immediate medical response, modeling can be used in advance to develop decision-making strategies that support specific approaches to prioritization of victims for treatment. The model of resource and time-based triage ${ }^{21}$ was built to test triage methods for prioritizing victims presenting to hospitals, given the likely pattern of casualties after a nuclear detonation.

The model considers the varying severity of traumatic injuries likely to result from a nuclear detonation: crush, blunt, and penetrating. The model also considers a range of resources (space, staff and supplies).,2,28 Because staff are required to use space and supplies, the model focuses on maximizing the efficiency of critical staff in a hospital by focusing staff on those for whom care will make the greatest difference in survivability.

The model predicts that in this scarce resources setting, the most lives will be saved if those with moderate life-threatening injuries are prioritized before those with the most severe lifethreatening injuries and those who are most likely to die. ${ }^{21}$ It indicates that people in the moderate category survive at a much greater rate ( $5 \%$ vs $30 \%$ mortality) if treated. In a constrainedresources environment, prioritizing injured people in the moderate category over people in the severe life-threatening injured category saves $50 \%$ more victims, and this increases in proportion as resources become more constrained. Figure 1 illustrates how this triage categorization may look in a scarceresources setting; however, it is but one of several charts that planners and responders need to consider together.

Before the establishment of incident command and full situational awareness, decisions will be made by providers. Ideally, medical facilities plan for managing scarce resources and put systems in place to implement those plans. Harmonizing an approach across a region would help ensure fairness. Once situational awareness and resources allow, a proactive approach would include a formal system such as a clinical care committee and a triage team with clearly defined operating and decision-making procedures. The importance of these groups is to make proactive triage decisions and to remove the decisions about resource allocation and triage for individual patients from the hands of their treating physician(s). ${ }^{2,23}$

\section{Challenges}

The challenges faced in triage after a nuclear detonation include the following:

For medical responders:

- Triage categories for nuclear incident are not well understood by providers and require preincident and just-in-time education.

- Medical management and the unfamiliarity with radiation injury and its treatment require preincident and just-intime education.

- The shift from the usual priorities of sickest first to moderate life-threatening injuries first is difficult for providers and requires a change in thinking.

- Iterative retriage is required because triage into the expectant category may not be a final categorization if more resources become available or conditions change.

- Surge capacity will require assistance from many untrained volunteers and the ability to move people to better resource settings. This will require excellent planning and incident management.

For laboratories:

- Laboratory capacity for biodosimetry (used to assess the radiation dose a person received), including hematology surge capacity for lymphocyte counts, must be expanded.

- High throughput technologies for point-of-care diagnostics are needed to cope with demand. Ideally, these would have dual utility beyond a nuclear detonation. (Research and development projects are in progress.)

For modeling and prediction:

- There is a lack of detailed understanding of time to death from various causes for untreated victims. This gap could be filled by primary research using existing data.

- Limited information is available on combined injury outcomes. Laboratory research is not possible for some injury types.

- The lack of understanding of the effects of a nuclear weapon on the medical system itself hampers predictions of response.

- There is a lack of understanding of what medical resources will be truly limited in relation to distance from the incident. This gap could begin to be addressed by a comprehensive modeling program that accounts for resource hierarchies, resource substitution, the cost of shortfalls, predicted evacuation times after the incident, and the ability to resupply and distribute resources from those already within the region. 


\section{FUTURE STEPS}

The goals of the Scarce Resources for a Nuclear Detonation Project are to provide useful information for planners and responders in advance of a nuclear detonation, to enhance the public's knowledge of actions and priorities after a nuclear detonation, and to encourage dialogue and preparation, because most jurisdictions remain underprepared for such an incident. The challenges identified in our deliberations will help define the next steps to be considered.

Updates regarding a nuclear detonation incident can be found in Planning Guidance for Response to a Nuclear Detonation ${ }^{4}$ and on the Radiation Emergency Medical Management, ${ }^{12}$ Centers for Disease Control and Prevention, ${ }^{33}$ Armed Forces Radiobiology Research Institute, ${ }^{11}$ National Institute for Arthritis and Infectious Diseases, ${ }^{9}$ and $\mathrm{ASPR}^{5}$ Web sites. Interested readers are encouraged to join the REMM listserv.

It is recognized that there is no single right or perfect solution for responding to a nuclear detonation, yet a well-considered response is possible. Efficiency (maximizing lives saved) is important, but fairness is the ethical principle that considers patients' needs as well as the effectiveness of the available resources in caring for patients. Although different individuals and communities may weigh the needs of the patients and the effectiveness of resources differently, ensuring fair and consistent treatment and symptom relief may be one of the most important factors in a successful response after a nuclear detonation. We anticipate that this special issue of Disaster Medicine and Public Health Preparedness and other tools will improve the awareness, preparedness, and resilience for response to a nuclear detonation, and will produce further discussion, appropriate adaptation, and ongoing progress. Through planning, preparing, exercising relevant scenarios, and applying these concepts, preparation for mass casualty incidents will continuously improve.

\section{APPENDIX}

At the initial Scarce Resources for a Nuclear Detonation Project meeting, experts presented background information on topics of relevance to the scarce resources setting of a nuclear detonation incident. The panel then identified topic areas for inclusion in the manuscripts that would be submitted for possible publication in the peer-reviewed literature. Each topic area had a lead author or authors assigned. The writing team for each manuscript ensured that there was broad representation of relevant expertise. Input was sought from the Radiation Injury Treatment Network at one of their group meetings ${ }^{13}$ to refine focus areas and create general consensus around strategies of medical response. Where necessary, the leads sought additional expertise such as modeling experts. The writing teams convened subgroup meetings to develop outlines and draft manuscripts. A second smaller meeting of the lead writers was hosted to ensure continuity and conceptual clarity across the manuscripts. The panel of experts provided internal peer review of the manuscripts before submitting them for possible publication. Consensus agreement was reached among the experts, or the areas of disagreement were cited in the manuscripts. In the end, 10 manuscripts were written to address the central topics. The manuscripts were submitted for peer review and potential publication in the scientific literature. An ad-

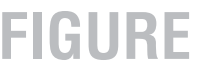

\section{Triage category for trauma and combined injury}

\begin{tabular}{|c|c|c|c|c|c|}
\hline \multicolumn{6}{|c|}{$\begin{array}{l}\text { Triage category for TRAUMA and COMBINED IN } \\
\text { Injury injury severity, radiation dose, and resource } \\
\text { severity }\end{array}$} \\
\hline \multirow{3}{*}{$\begin{array}{l}\geq \text { Moderate } \\
\text { trauma* }+ \\
\text { radiation } \\
>2 \mathrm{~Gy}^{* *}\end{array}$} & \multirow{2}{*}{\multicolumn{2}{|c|}{ Immediate }} & Delayed & Expectant & Expectant \\
\hline & & & Immediate & Delayed & Expectant \\
\hline & \multicolumn{2}{|c|}{ Trauma only } & \multicolumn{3}{|c|}{$\begin{array}{c}\text { BURN > } 20 \% \text { BSA worsens triage category } \\
\text { (lowers priority) } 1-2 \text { levels }\end{array}$} \\
\hline $\begin{array}{l}\text { Severe } \\
\text { trauma* }\end{array}$ & \multicolumn{2}{|c|}{ Immediate } & Immediate & Delayed & Expectant \\
\hline $\begin{array}{l}\text { Moderate } \\
\text { trauma* }\end{array}$ & \multicolumn{2}{|c|}{ Delayed } & Delayed & Immediate & Immediate \\
\hline $\begin{array}{l}\text { Minimal } \\
\text { trauma* }\end{array}$ & \multicolumn{2}{|c|}{ Minimal } & Minimal & Minimal & Minimal \\
\hline $\begin{array}{l}\text { Resource } \\
\text { availability: }\end{array}$ & \multicolumn{2}{|c|}{ Normal } & Good & Fair & Poor \\
\hline $\begin{array}{l}\text { Standard of } \\
\text { care }^{* *}:\end{array}$ & \multicolumn{2}{|c|}{ Conventional } & Contingency & Crisis & Crisis \\
\hline \multicolumn{6}{|c|}{ Legend: Trauma and combined injury } \\
\hline \multicolumn{6}{|c|}{$\begin{array}{l}\text { *Adding }>20 \% \text { total body surface area burn to trauma worsen triage } \\
\text { priority by } 1 \text { category (puts them lower on the priority list). } \\
* * \text { Radiation dose received by the whole body or a significant portion of the } \\
\text { whole body. At higher radiation doses ( }>6 \text { Gy), triage category may } \\
\text { worsen-as on Combined Injury card. } \\
\text { ***Institute of Medicine. Guidance for establishing crisis standards of care } \\
\text { for use in disaster situations: } A \text { letter report. Washington, DC: Institute } \\
\text { of Medicine, National Academies of Science; } 2009 \text {. }\end{array}$} \\
\hline \multicolumn{2}{|c|}{ Trauma category } & \multicolumn{4}{|c|}{ Description } \\
\hline \multicolumn{2}{|c|}{ Combined injury } & \multicolumn{4}{|c|}{$\begin{array}{l}\text { - Radiation dose of }>2 \text { Gy to whole body or significant } \\
\text { portion of whole body plus moderate or severe trauma } \\
\text { and/or burn injury. }\end{array}$} \\
\hline \multicolumn{2}{|c|}{ Severe trauma } & \multicolumn{4}{|c|}{$\begin{array}{l}\text { - Stabilization requires complex treatment; } \\
\text { - }>20 \% \text { chance of death even with treatment. }\end{array}$} \\
\hline \multicolumn{2}{|c|}{ Moderate trauma } & \multicolumn{4}{|c|}{$\begin{array}{l}\text { - Without stabilization, potential for death within hours } \\
\text { - }<20 \% \text { chance of death with stabilization and } \\
\text { treatment. }\end{array}$} \\
\hline \multicolumn{2}{|c|}{ Minimal trauma } & \multicolumn{4}{|c|}{$\begin{array}{l}\text { - Injuries pose no significant risk to life and limb in next } \\
\text { 3-4 days } \\
\text { - Limited or no treatment prior to referral in the next } \\
\text { 3-4 days. }\end{array}$} \\
\hline
\end{tabular}

This is 1 of a series of "cards" that indicates how triage category changes based on the availability of resources for trauma and combined injury. These are discussed in detail in

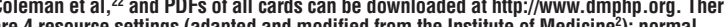
are 4 resource settings (adapted and modified from the institute of Medicine'): normal, tion of resources allows normal triage order crisis, which is subdivided into fair, when there are enough resources to treat the moderate life-threatening trauma, and poor, when there are insufficient resources to treat the moderates. The injury severity categories are there are insufficient resources to treat the moderates. The injury severity categories are ment is available $\mathrm{e}^{21} ;$ moderate life threatening, in which the injuries are less severe and mortality is $<20 \%$; minimal, in which the injuries may require intervention, even substantial intervention, but are not life threatening within the next day or so (eg, certain limb fractures); and combined injury, which is moderate or severe life-threatening injury plus a radiation dose of $>2$ Gy (lower doses are not considered to be combined injury and are triaged as trauma only). Burns of $>\mathbf{2 0} \%$ total body surface area worsen triage category 1 level (eg, delayed to expectant). In the conventional and contingency settings, the usual sickest first" order is followed by severe receiving immediate care, then moderate, and minimal after that (although in a mass casualty setting, some of the minimal may be given temporary remedies and sent on for definitive care, as with a splint or bandage for fracture or non-life-threatening wound). In the crisis setting with fair resources, moderates would be treated before severes; with poor resources, moderates would be treated first, recognizing there are not even sufficient resources for them. In general, individuals with combined injury would be treated similarly to the severe, although at the higher radiation doses survival is so limited that they may receive a lower priority (eg, in crisis, fair resources delayed may be changed to expectant). Reevaluation is a key part of triage and managemen severe) and as resource setting improves (eg, a delayed may become an immediate). 
ditional background paper was added after the initial review based on feedback from the editors of Disaster Medicine and Public Health Preparedness.

The participants who attended the March 5, 2009 executive steering committee meeting for the Scarce Resources for a Nuclear Detonation Project are listed below.

CAPT Judith Bader, MD, Radiation Oncologist, Senior Medical Advisor, NCI/NIH; Sylvia Brugge, Project Coordinator, DHHS; Brooke Buddemeier, CHP, Lawrence Livermore National Laboratory; Stephen V. Cantrill, MD, Principal Investigator Associate Director, Emergency Medical Services, BNICE Training Center, Department of Emergency Medicine, Denver Health Medical Center; Jamie Caro, MD, Senior Vice President, Health Economics, United BioSource Corporation; Rocco Casagrande, PhD, Managing Director, Gryphon Scientific; Nelson J. Chao, MD, Director, Duke University Bone Marrow and Stem Cell Transplant Program; C. Norman Coleman, MD, Associate Director, Radiation Research Program, Division of Cancer Treatment and Diagnosis, NCI/NIH; Susan CollerMonarez, PhD, Program Analyst/Project Officer, OPEO; Evan DeRenzo, PhD, Senior Clinical Bioethicist, Center for Ethics, Washington Hospital Center; Daniel Dodgen, PhD, Director, Office for At Risk Individuals, Behavioral Health, and Human Services Coordination, ASPR/DHHS; Richard Hatchett, MD, Associate Director, Radiation Countermeasures Research and Emergency Preparedness, NIAID/DAIT; COL Pat Lillis-Hearn, MD, Director, Armed Forces Radiobiology Research Institute Uniformed Services University; John L. Hick, MD, Medical Director, Hennepin County Medical Center, Department of Emergency Medicine, University of Minnesota; Mary Beth Hill-Harmon, MSPH, Project Officer/Program Analyst, Modeling, BARDA/ASPR/DHHS; Jerry Holmberg, PhD, Senior Advisor for Blood Policy, DHHS, Executive Secretary, Advisory Committee on Blood Safety and Availability; Jimmie Jacobs, PhD, Senior Analyst, SAIC Contractor in Support of BARDA/ASPR/DHHS; Gabor D. Kelen, MD, FACEP, FAAEM, FRCP(C), Professor and Chair, Department of Emergency Medicine, Director, Office of Critical Event Preparedness and Response, Director, Center for the Study of Preparedness and Catastrophic Event Response, Johns Hopkins University; RADM Ann Knebel, DNSc, Deputy Director, Office of Preparedness Planning, OPEO/ASPR/DHHS; Alicia Livinski, MPH, MA, Biomedical Librarian, NIH Library; Bert Maidment, MD, Associate Director, Product Development, NIAID/DAIT/NIH; Ron Manning, PhD, Chief, Chemical, Radiological and Nuclear Medical Countermeasures, Division of CBRN Countermeasures, BARDA/ASPR; Marianne Matzo, $\mathrm{PhD}, \mathrm{APRN}, \mathrm{BC}, \mathrm{FAAN}$, Professor and Frances E. and Earl Ziegler Chair in Palliative Care, Palliative Care Nursing, University of Oklahoma College of Nursing; Paula Murrain-Hill, MPH, Senior Management Policy Analyst OPEO/ASPR/DHHS; CAPT Jeff Nemhauser, MD, US Public Health Service, CDC, National Center for Environmental Health, Division of Environmental Hazards \& Health Effects, Radiation Studies Branch;
COL Ann Norwood, MD (Ret.), Senior Associate, Center for Biosecurity of UPMC; Jon Perez, PhD, Behavioral Health Consultant, Office of Clinical and Preventive Services, Indian Health Service; Sally Phillips, RN, PhD, Director, Office of Public Health Emergency Preparedness, Agency for Healthcare Research and Quality ; Lewis Rubinson, MD, PhD, Disaster Medicine Director, Public Health Seattle and King County, Senior Medical Advisor, CDC; Jack Sava, MD, Director Trauma/ Acute Care Surgery, Washington Hospital Center; Susan Sherman, JD, Senior Attorney, Office of the General Counsel, DHHS; Tammy Taylor, PhD, Senior Policy Analyst, Office of Science and Technology Policy, Executive Office of the President; Richard Waldhorn, MD, Distinguished Scholar, Center for Biosecurity of UPMC; David Weinstock, MD, Assistant Professor, Dana-Farber Cancer Institute, Department of Medical Oncology, Harvard Medical School.

Abbreviation key: ASPR $=$ Assistant Secretary for Preparedness and Response; BARDA = Biomedical Advanced Research and Development Authority; CBRN = chemical, biological, radiological, nuclear; $\mathrm{CDC}=$ Centers for Disease Control and Prevention; DAIT = Division of Allergy, Immunology, and Transplantation; DHHS = Department of Health and Human Services; NIAID $=$ National Institute of Allergy and Infectious Diseases; $\mathrm{NCI}=$ National Cancer Institute; $\mathrm{NIH}=$ National Institutes of Health; OPEO= Office of Preparedness and Emergency Operations; $\mathrm{SAIC}=$ Science Applications International Corporation; UPMC = University of Pittsburgh Medical Center.

Author Affiliations: Drs Coleman, Knebel, Dodgen, Cliffer, and Bader and Ms Murrain-Hill are with the Office of the Assistant Secretary for Preparedness and Response, US Department of Health and Human Services; Dr Hick is with the Hennepin County Medical Center, University of Minnesota; Dr Weinstock is with the Dana-Farber Cancer Institute, Harvard Medical School; Dr Casagrande is with Gryphon Scientific; Dr Caro is with the Department of Epidemiology, Biostatistics and Occupational Health, Division of General Internal Medicine, McGill University; Dr DeRenzo is with the Center for Ethics, Washington Hospital Center; Dr Norwood is with the Center for Biosecurity of the University of Pittsburgh Medical Center; Ms Sherman is with the Office of the General Counsel, US Department of Health and Human Services; and $\mathrm{Mr}$ McNally is with Science Applications International Corporation.

Correspondence: Address correspondence and reprint requests to Dr C. Norman Coleman, Office of the Assistant Secretary for Preparedness and Response, US Department of Health and Human Services, 6130 Executive Blvd, Rockville, MD 20852 (e-mail: Norman.Coleman@nih.gov).

Received for publication September 19, 2010; accepted January 18, 2011.

The US Department of Health and Human Services (DHHS) provided funding to support this publication and convene the authors. The contents of the articles represent the personal views of the individual authors and do not necessarily express the opinion or policy of DHHS or its components. No statement in the articles should be construed as an official position of DHHS or its components.

Author Disclosures: The authors report no conflicts of interest.

Acknowledgment: The authors acknowledge the contribution of Alicia Livinski, biomedical librarian, National Institutes of Health Library, for assistance with the preparation of this article. 


\section{REFERENCES}

1. The Next Challenge in Healthcare Preparedness. Catastrophic Health Events. Baltimore, MD: Center for Biosecurity, University of Pittsburgh Medical Center; 2009.

2. Institute of Medicine. Guidance for Establishing Crisis Standards of Care for Use in Disaster Situations: A Letter Report. Washington, DC: National Academies of Science; 2009.

3. Kaji A, Koenig KL, Bey T. Surge capacity for healthcare systems: a conceptual framework. Acad Emerg Med. 2006;13(11):1157-1159.

4. Planning Guidance for Response to a Nuclear Detonation. 2nd ed. Washington, DC; Homeland Security Council, Interagency Policy Coordination Subcommittee for Preparedness and Response to Radiological and Nuclear Threats; May 6, 2010. http://hps.org/hsc/documents/Planning _Guidance_for_Response_to_a_Nuclear_Detonation-2nd_Edition_FINAL .pdf. Accessed February 7, 2011.

5. Office of the Assistant Secretary for Preparedness and Response Web site. Accessed June 23, 2010. http://www.phe.gov/about/Pages/default.aspx.

6. Barbera JA, Macintyre AG. Medical Surge Capacity and Capability Handbook: A Management System for Integrating Medical and Health Resources During Large-Scale Emergencies. http://www.hhs.gov/disasters/discussion /planners/mscc/mscc080626.pdf. Published 2007. Accessed May 15, 2010.

7. Coleman CN, Hrdina C, Bader JL, et al. Medical response to a radiologic/ nuclear event: integrated plan from the Office of the Assistant Secretary for Preparedness and Response, Department of Health and Human Services. Ann Emerg Med. 2009;53(2):213-222.

8. Hrdina CM, Coleman CN, Bogucki S, et al. The "RTR" medical response system for nuclear and radiological mass-casualty incidents: a functional TRiage-TReatment-TRansport medical response model. Prehosp Disaster Med. 2009;24(3):167-178.

9. National Institute of Allergy and Infectious Diseases, National Institutes of Health. Medical countermeasures against radiological and nuclear threats. http://www3.niaid.nih.gov/topics/radnuc. Accessed February 11, 2010.

10. Office of the Assistant Secretary for Preparedness and Response. Biomedical Advanced Research and Development Authority. http://www.hhs.gov /aspr/barda. Accessed May 6, 2010.

11. Military Medical Operations, Armed Forces Radiobiology Research Institute, US Department of Defense. Medical Management of Radiological Casualties Handbook. Bethesda, MD: Armed Forces Radiobiology Research Institute; 2003.

12. National Library of Medicine, National Institutes of Health. Radiation Emergency Medical Management. http://www.remm.nlm.gov. Accessed April 2, 2010.

13. Radiation Injury Treatment Network. Accessed February 14, 2010. http://www.nmdp.org/RITN/index.html.

14. DiCarlo AL, Maher C, Hick JL, et al. Radiation injury after a nuclear detonation: medical consequences and the need for scarce resources allocation. Disaster Med Public Health Prep. 2011;5(Suppl 1):S32-S44.

15. Knebel AR, Coleman CN, Cliffer KD, et al. Allocation of scarce resources after a nuclear detonation: setting the context. Disaster Med Public Health Prep. 2011;5(Suppl 1):S20-S31.

16. Hick JL, Weinstock DM, Coleman CN, et al. Health care system planning for and response to a nuclear detonation. Disaster Med Public Health Prep. 2011;5(Suppl 1):S73-S88.

17. Caro JJ, DeRenzo EG, Coleman CN, et al. Resource allocation after a nuclear detonation incident: unaltered standards of ethical decision making. Disaster Med Public Health Prep. 2011;5(Suppl 1):S46-S53.

18. Dodgen D, Norwood AE, Becker SM, et al. Social, psychological and behavioral responses to a nuclear detonation in a US city: implications for health care planning and delivery. Disaster Med Public Health Prep. 2011; 5(Suppl 1):S54-S64.

19. Sherman SE. Legal considerations in a nuclear detonation. Disaster Med Public Health Prep. 2011;5(Suppl 1):S65-S72.

20. Murrain-Hill P, Coleman CN, Hick JL, et al. Medical response to a nuclear detonation: creating a playbook for state and local planners and responders. Disaster Med Public Health Prep. 2011;5(Suppl 1):S89-S97.

21. Casagrande R, Wills N, Kramer E, et al. Using the model of resource and time-based triage (MORTT) to guide scarce resource allocation in the aftermath of a nuclear detonation. Disaster Med Public Health Prep. 2011; 5(Suppl 1):S98-S110.

22. Coleman CN, Weinstock DM, Casagrande R, et al. Triage and treatment tools for use in a scarce resources-crisis standards of care setting after a nuclear detonation. Disaster Med Public Health Prep. 2011;5(Suppl 1):S111-S121.

23. Christian MD, Devereaux AV, Dichter JR, Geiling JA, Rubinson L. Definitive care for the critically ill during a disaster: current capabilities and limitations: from a Task Force for Mass Critical Care summit meeting, January 26-27, 2007, Chicago, IL. Chest. 2008;133(5)(Suppl):8S$17 \mathrm{~S}$.

24. Devereaux A, Christian MD, Dichter JR, Geiling JA, Rubinson L; Task Force for Mass Critical Care. Summary of suggestions from the task force for mass critical care summit, January 26-27, 2007. Chest. 2008;133(5) (Suppl):1S-7S.

25. Devereaux AV, Dichter JR, Christian MD, et al; Task Force for Mass Critical Care. Definitive care for the critically ill during a disaster: a framework for allocation of scarce resources in mass critical care: from a Task Force for Mass Critical Care summit meeting, January 26-27, 2007, Chicago, IL. Chest. 2008;133(5)(Suppl):51S-66S.

26. Rubinson L, Hick JL, Curtis JR, et al; Task Force for Mass Critical Care. Definitive care for the critically ill during a disaster: medical resources for surge capacity: from a Task Force for Mass Critical Care summit meeting, January 26-27, 2007, Chicago, IL. Chest. 2008;133(5)(Suppl):32S-50S.

27. Rubinson L, Hick JL, Hanfling DG, et al; Task Force for Mass Critical Care. Definitive care for the critically ill during a disaster: a framework for optimizing critical care surge capacity: from a Task Force for Mass Critical Care summit meeting, January 26-27, 2007, Chicago, IL. Chest. 2008; 133(5)(Suppl):18S-31S.

28. Veterans Health Administration Pandemic Ethics Initiative Work Group. Meeting the Challenge of Pandemic Influenza: Ethical Guidance for Leaders and Health Care Professionals in the Veterans Health Administration. http: //www.ethics.va.gov/activities/pandemic_influenza_preparedness.asp. Published July 2010. Accessed August 1, 2010.

29. Agency for Healthcare Research and Quality. Mass Medical Care With Scarce Resources: A Community Planning Guide. AHRQ Publication No. 070001. http://www.ahrq.gov/research/mce. Published February 2007. Accessed June 23, 2010.

30. Agency for Healthcare Research and Quality. Medical Care With Scarce Resources: The Essentials. AHRQ Publication No. 09-0016. http://www .ahrq.gov/prep/mmcessentials. Published September 2009. Accessed June 23, 2010.

31. Lerner EB, Schwartz RB, Coule PL, et al. Mass casualty triage: an evaluation of the data and development of a proposed national guideline. Disaster Med Public Health Prep. 2008;2(Suppl 1):S25-S34.

32. Office of the Assistant Secretary for Preparedness and Response. National Disaster Medical System Web site. http:/www.phe.gov/Preparedness /responders/ndms/Pages/default.aspx. Accessed June 23, 2010.

33. Centers for Disease Control and Prevention. Radiation Studies Branch Web site. http://www.cdc.gov/nceh/radiation. Accessed February 14, 2010. 